\title{
Titin and dystrophin serum concentration changes in patients affected by thyroid disorders
}

\author{
Ariadna Zybek-Kocik', Nadia Sawicka-Gutaj', Remigiusz Domin ${ }^{1}$, Ewelina Szczepanek-Parulska' , \\ Tomasz Krauze'2, Przemysław Guzik², Marek Ruchała ${ }^{2}$ \\ ${ }^{1}$ Department of Endocrinology, Metabolism, and Internal Medicine, Poznan University of Medical Sciences, Poznań, Poland \\ ${ }^{2}$ Department of Cardiology-Intensive Therapy and Internal Medicine, Poznan University of Medical Sciences, Poznań, Poland
}

\begin{abstract}
Introduction: It is well established that thyroid hormones significantly affect skeletal muscle function, causing symptoms like myalgia and muscle weakness. Hypothyroid patients present increased levels of creatine kinase (CK), indicating muscle destruction. Lately, we proposed new serum markers of muscle disturbances in thyroid disorders: titin (TTN) and dystrophin (DMD). The aim of this study is to determine the association between thyroid status, muscle metabolism, and serum levels of TTN and DMD in patients affected by hypoand hyperthyroidism, before and after the treatment.

Material and methods: In the study 56 subjects were enrolled. The studied group consisted of 16 patients with newly diagnosed overt hypothyroidism and 20 patients with hyperthyroidism. Twenty healthy controls were also included in the study. Body composition, thyroid hormones, and biochemical markers of muscle deterioration levels were evaluated before and after restoration of euthyroidism. Results: Dystrophin and TTN levels were noticeably lower in the hypothyroid group and hyperthyroid group in comparison with controls, at the border of statistical significance. Along with the thyroid hormones and CK normalisation, DMD levels increased in the hypothyroid group, with no significant lowering of TTN levels. However, TTN concentrations and the fT3/fT4 ratio became significantly lower than in controls. Hyperthyroid patients experienced no significant changes in TTN and DMD.

Conclusions: The presented data indicate that TTN and DMD are potential new markers of musculoskeletal deterioration in thyroid disorders. In addition, the shift in TTN and DMD serum concentrations after the treatment of hypothyroidism accompanied by decreased fT3/fT4 ratio suggest the influence of the chosen therapeutic approach on muscle metabolism. (Endokrynol Pol 2021; 72 (1): 1-7)

Key words: hypothyroidism; hyperthyroidism; muscle tissue; titin; dystrophin
\end{abstract}

\section{Introduction}

Patients affected by thyroid disorders, including those suffering from hypothyroidism and those with hyperthyroidism, often report accompanying muscular symptoms such as weakness, fatigability, muscle pain, stiffness, or cramps. However, the prevalence of these signs and symptoms is variable [1-4].

The majority of these symptoms, except in muscle strength, can be evaluated only subjectively by the patient. Kocabas et al. [5] showed that the muscle strength of patients with hypo- or hyperthyroidism is significantly reduced in comparison to the control group. Interestingly, after restoring euthyroidism, the strength parameters improved only in the hyperthyroid group; this may be related to the fact that hypothyroidism usually lasts much longer than hyperthyroidism until the moment of treatment, which may lead to irreversible changes at the cellular level of the muscles.

Due to the high complexity of the muscle cells' physiology and the importance of thyroid hormones in their homeostasis $[6,7]$, the direct cause of the symptoms mentioned above cannot be clearly identified yet. In the case of overt hypothyroidism, the negative influence of thyroid disorder on muscle tissue can be visualised by the elevation of creatine kinase (CK) activity, as well as lactate dehydrogenase (LDH) in serum [8]. The CK serum activity, because it is a component of the muscle fibre cytosol, is generally positively correlated with progressing muscle damage [9] Although similar changes do not appear in hyperthyroid patients, these subjects usually experience a statistically significant decrease in CK levels due to increased renal filtration, visualised by elevated estimated glomerular filtration rate (eGFR) [10]. Other useful markers of muscle dysfunction in the case of thyroid function disturbances have not been widely described to date.

In the recent study conducted by our team in 2018 [11], the new markers of disturbances in muscle tissue metabolism due to changes in the thyrometabolic states were proposed. Decreased titin (TTN) and dystrophin 
(DMD) serum concentrations were shown on a large group of patients affected by overt hypo- or hyperthyroidism, compared with healthy controls. The authors hypothesised that changes in serum concentrations of these large, structural muscle tissue proteins might reflect the alterations in muscle tissue metabolism. It was concluded, because the dynamics of those changes were in contrast to the case of $\mathrm{CK}$, that the dysfunction of muscle fibres might be the result of decreased production of these proteins, not leakage from destructed cells. It is worth noting that it was the first description of the dynamics of changes of TTN and DMD and their potential usefulness in the assessment of thyroid disorders. However, the serum concentrations of TTN and DMD have not yet been evaluated after the restoration of euthyroidism.

The aim of this study is to determine the association between thyroid status and serum levels of TTN and DMD in patients affected by overt hypo- and hyperthyroidism, before and after the restoration of euthyroidism, which could provide more data on the impact of thyroid disease on muscle tissue metabolism.

\section{Material and methods}

\section{Enrolled subjects}

The study was conducted among the population of the Wielkopolskie Voivodeship in Poland. All participants are Caucasians of Polish origin. A total of 56 subjects were enrolled in the study. The studied group consisted of 16 patients with newly diagnosed severe overt hypothyroidism due to autoimmune thyroid disease and 20 treatment-naive patients with severe overt hyperthyroidism affected by Graves' disease. Additionally, 20 healthy control subjects were included in the study. The exclusion criteria were similar to those applied in the previous researches [11]. The Bioethical Committee at Poznan University of Medical Sciences approved the study (Resolution no. 923/13).

\section{Study protocol}

All engaged subjects underwent a full clinical examination, thyroid ultrasound, and assessment of body composition. The laboratory measurements included irisin concentrations, thyroid-related hormones concentrations (thyroid-stimulating hormone [TSH], free triiodothyronine [fT3], free thyroxine [fT4]), titres of anti-thyroid autoantibodies (serum anti-thyroid peroxidase antibodies [TPOAb], anti-thyroglobulin antibodies [TgAb], anti-TSH receptor autoantibodies [TRAb/TRAK]), and muscle protein concentrations as biochemical markers of muscle dysfunction and/or injury (CK, DMD, TTN). Additionally, serum fasting glucose concentrations were measured, and the fT3/fT4 ratio was calculated. The body composition assessment was performed using bioelectrical impedance analysis (BIA), assessing body weight, body mass index (BMI), fat mass (FM), percent of fat mass (Fat\%), free-fat mass (FFM), muscle mass (MM), and visceral fat rating. Venous blood samples were gathered and BIA analysed in a consistent manner after 8 hours of fasting. All measurements were repeated after restoring euthyroidism due to applied treatment - L-thyroxine substitution in hypothyroid patients, treatment with anti-thyroid drugs, radioiodine therapy, or thyroidectomy in the case of hyperthyroidism.
The measurements of TSH, fT3, fT4, CK, and glucose concentrations were done with the use of a Hitachi Cobas e601 chemiluminescent analyser (Roche Diagnostics). Thyroid autoantibody concentrations were assessed by a radioimmunological method with the use of commercially available BRAMHS anti-TPO, anti-Tg, and TRAK RIA kits, and a scintillation gamma counter (LKB Wallac Clini Gamma 1272). Irisin serum concentration was measured using ELISA Assay Kit from Phoenix Pharmaceuticals - Catalogue No. EK-067-29 - Irisin, Recombinant (Human, Rat, Mouse, Canine) ELISA Kit. DMD and TTN concentrations were evaluated with ELISA Assay Kit by Shanghai Sunred Biological Technology. Both kits (Catalogue No. 201-12-5116 for TTN and 201-12-1446 for DMD) are based on the principle of double-antibody sandwich technique, with the use of monoclonal antibodies. These assays have high sensitivity and specificity for the detection of TTN and DMD, and no significant cross-reactivity of interference between TTN/DMD and their analogues was observed. The AIXPLORER system by Supersonic Imagine was used for ultrasonographic examination of the thyroid gland, and the Tanita MC 180 MA analyser was used for the evaluation of body composition. The used normal ranges included: TSH $-0.27-4.2 \mu \mathrm{IU} / \mathrm{ml}$, fT3 - 3.90-6.70 pmol/L, fT $4-11.5-21.0$ $\mathrm{pmol} / \mathrm{L}, \mathrm{CK}-26.0-140.0 \mathrm{U} / \mathrm{L}$, glucose $-70.0-99.0 \mathrm{mg} / \mathrm{dL}$, TRAb $<2.0 \mathrm{IU} / \mathrm{L}, \mathrm{TPOAb}<34 \mathrm{IU} / \mathrm{mL}, \mathrm{TgAb} 10-115 \mathrm{IU} / \mathrm{mL}$.

\section{The diagnosis}

When the TSH concentration exceeded the reference range and free thyroid hormones were below the normal values, the diagnosis of overt hypothyroidism was established. Enrolled patients were diagnosed with overt hyperthyroidism on the other hand, when a decrease in TSH concentration below the normal value occurred, along with an increase in free thyroid hormones concentrations above the reference range. To establish the diagnosis of autoimmune thyroid disease, the detection of at least one elevated anti-thyroid autoantibody titre and presence of sonographic signs of chronic thyroid inflammation were required. Overt hyperthyroidism accompanied by the elevation of TRAb titres and typical thyroid ultrasound features was mandatory for the diagnosis of Graves' disease.

\section{Statistical analysis}

STATISTICA software by StatSoft was applied to analyse the acquired data. Normality was checked by the Shapiro-Wilk test, and the equality of variances was analysed with the use of Levene's test. Taking into consideration the small size of the analysed groups, statistically significant differences in normality, and equality of variances between groups, non-parametric tests were used. To compare analysed parameters between two groups, a two-tailed Mann-Whitney U test was applied, while for more than two groups, Kruskal-Wallis one-way analysis of variance was used with the following post-hoc analysis. To analyse the difference between the two related samples, the Wilcoxon signed-rank test was used. A p-value of less than 0.05 was considered statistically significant.

\section{Results}

Bodyweight, age, BMI, FM, FFM, Fat $\%$, MM, and visceral fat rating have not differed significantly between the study groups at baseline and controls, as well as gender distribution; however, the difference in bodyweight and FM between groups almost reached statistical significance (Tab. 1). Nevertheless, BMI and Fat $\%$ seem to be more objective parameters, because they take into account the differences in the height of patients. The analysed groups presented significantly different levels of TSH, fT4, fT3, CK, aTPO, aTg, and $\mathrm{TRAb}$. The glucose levels were increased in the hyper- 
Table 1. The characteristics and statistical differences of the measured values at baseline in three study groups: patients affected by hyperthyroidism, those affected by hypothyroidism, and controls. Statistically significant differences $(p<0.05)$ are marked $\left[{ }^{*}\right]$

\begin{tabular}{|c|c|c|c|c|}
\hline $\begin{array}{l}\text { Median } \\
\text { [25-75\%] }\end{array}$ & Hyperthyroidism & Hypothyroidism & Controls & $\mathrm{p}$ value \\
\hline Age & 43.00 & 37.00 & 40.00 & \multirow{2}{*}{0.9580} \\
\hline [y] & [27.00-58.00] & [31.00-46.00] & [33.50-50.50] & \\
\hline TSH & 0.01 & 98.77 & 2.40 & \multirow{2}{*}{$<0.0001^{*}$} \\
\hline$[\mathrm{pmol} / \mathrm{L}]$ & {$[0.01-0.01]$} & [80.05-100.00] & [1.76-2.73] & \\
\hline fT3 & 27.21 & 1.56 & 5.18 & \multirow{2}{*}{$<0.0001 *$} \\
\hline$[\mathrm{pmol} / \mathrm{L}]$ & [20.53-32.39] & [0.84-1.86] & [4.67-5.50] & \\
\hline fT4 & 73.69 & 2.51 & 15.44 & \multirow{2}{*}{$<0.0001^{*}$} \\
\hline$[\mathrm{pmol} / \mathrm{L}]$ & [53.73-81.03] & [1.83-4.32] & [14.74-17.55] & \\
\hline \multirow{2}{*}{ fT3/fT4 ratio } & 0.43 & 0.38 & 0.33 & \multirow{2}{*}{$0.004^{*}$} \\
\hline & [0.40-0.60] & {$[0.35-0.40]$} & [0.28-0.35] & \\
\hline TPOAb & 102.00 & 152.00 & 8.00 & \multirow{2}{*}{$<0.0001^{*}$} \\
\hline$[\mathrm{IU} / \mathrm{mL}]$ & [25.00-140.00] & [14.00-543.00] & [6.50-13.50] & \\
\hline $\operatorname{TgAb}$ & 235.50 & 106.00 & 10.00 & \multirow{2}{*}{$<0.0001^{*}$} \\
\hline$[\mathrm{IU} / \mathrm{mL}]$ & [64.00-478.50] & [28.00-669.00] & [10.00-19.00] & \\
\hline TRAb & 8.25 & 0.59 & 0.27 & \multirow{2}{*}{$<0.0001^{*}$} \\
\hline$[\mathrm{IU} / \mathrm{L}]$ & [4.70-9.29] & [0.33-2.55] & [0.19-0.30] & \\
\hline CK & 47.00 & 299.00 & 105.00 & \multirow{2}{*}{$<0.0001^{*}$} \\
\hline$[\mathrm{IU} / \mathrm{L}]$ & [43.00-62.00] & [225.00-419.00] & [65.00-125.00] & \\
\hline DMD & 1.98 & 1.89 & 4.95 & \multirow{2}{*}{0.0639} \\
\hline$[\mathrm{ng} / \mathrm{mL}]$ & [1.36-5.75] & [1.61-5.78] & [2.13-7.43] & \\
\hline TTN & 12.07 & 13.33 & 42.00 & \multirow{2}{*}{0.0509} \\
\hline$[\mathrm{ng} / \mathrm{mL}]$ & [8.59-44.18] & [8.22-40.33] & [19.44-48.86] & \\
\hline Glucose & 101.00 & 85.50 & 89.00 & \multirow{2}{*}{$0.0036^{*}$} \\
\hline$[\mathrm{mg} / \mathrm{dL}]$ & [94.00-102.50] & [83.00-91.00] & [82.00-96.00] & \\
\hline Irisin & 152.40 & 105.84 & 153.00 & \multirow{2}{*}{$<0.0001$} \\
\hline$[\mathrm{ng} / \mathrm{mL}]$ & [126.45- 159.90] & [85.44-113.76] & [132.60-179.70] & \\
\hline Body weight & 59.40 & 64.58 & 66.78 & \multirow{2}{*}{0.0504} \\
\hline$[\mathrm{kg}]$ & [52.00-64.30] & [58.05-74.70] & [59.75-74.52] & \\
\hline Fat $\%$ & 23.50 & 26.40 & 25.30 & \multirow{2}{*}{0.2186} \\
\hline$(\%)$ & [19.70-25.70] & [20.30-28.20] & [22.30-33.75] & \\
\hline FM & 13.75 & 16.68 & 19.53 & \multirow{2}{*}{0.0553} \\
\hline$[\mathrm{kg}]$ & [9.95-15.55] & [12.90-19.75] & [14.60-22.75] & \\
\hline FFM & 45.95 & 49.98 & 46.68 & \multirow{2}{*}{0.2023} \\
\hline$[\mathrm{kg}]$ & [40.65-48.55] & [42.90-53.20] & [43.15-50.78] & \\
\hline MM & 43.60 & 47.43 & 44.30 & \multirow{2}{*}{0.1964} \\
\hline$[\mathrm{kg}]$ & [38.60-46.10] & [40.70-50.50] & [40.98-48.20] & \\
\hline BMI & 22.10 & 23.50 & 20.30 & \multirow{2}{*}{0.1301} \\
\hline$\left[\mathrm{kg} / \mathrm{m}^{2}\right]$ & [19.50-22.90] & [21.50-25.10] & [20.95-26.20] & \\
\hline \multirow{2}{*}{ Visceral fat rating } & 3.00 & 4.00 & 3.50 & \multirow{2}{*}{0.8317} \\
\hline & {$[1.00-5.00]$} & [3.00-5.00] & [1.50-7.00] & \\
\hline
\end{tabular}

TSH — thyroid-stimulating hormone; fT3 — free triiodothyronine; fT4 — free thyroxine; TPOAb — anti-thyroid peroxidase antibodies; TgAb — anti-thyroglobulin antibodies; TRAb — anti-TSH receptor autoantibodies; CK — creatine kinase; DMD — dystrophin; TTN — titin; BMI — body mass index; FM — fat mass, Fat $\%$ — percentage of fat mass; FFM — free-fat mass; MM — muscle mass 
thyroid group compared with hypothyroid patients and controls. Hypothyroid patients presented decreased concentrations of irisin in comparison with the other two groups which did not differ statistically in this respect. The difference in DMD and TTN concentrations between groups did not reach statistical significance; however, DMD and TTN levels were noticeably lower in the hypothyroid group and hyperthyroid group in comparison with controls. Before treatment in the hypothyroid and hyperthyroid groups the fT3/fT4 ratio was higher than in controls; however, in the second group at the border of statistical significance. The detailed results are presented in Table 1.

The mean observation time for reaching hormonal normalisation was 313.40 days or approximately 10.28 months for the hypothyroid group and 225.67 days or approximately 7.40 months for the hyperthyroid group. The hypothyroid group after the restoration of euthyroidism experienced slight weight loss, and a decrease in MM and FFM at the border of statistical significance (Tab. 2). There was no difference in FM and Fat $\%$. Along with the TSH, fT3, and fT4 normalisation, these patients showed normalisation of CK levels and significant increase in irisin and DMD levels. Median TTN concentrations were lower after achieving euthyroidism, but the difference was not statistically significant. In the hyperthyroid group after normalisation of thyroid hormones, we can observe an increase in body weight, BMI, FM, Fat \%, and CK levels and a decrease in glucose concentrations. There was no statistically significant change in MM, TTN, DMD, and irisin levels. In both groups, the fT3/fT4 ratio decreased after treatment.

After the treatment, patients in study groups did not differ statistically in body composition, as well as $\mathrm{TSH}$, fT3, fT4, CK, DMD, and glucose, compared with controls. The TTN levels were significantly lower in the hypothyroid group after achieving euthyroidism than in controls. The fT3/fT4 ratio was significantly lower in the hypothyroid group compared with the hyperthyroid group and controls, with no significant difference between hyperthyroid patients and controls. The detailed results are presented in Table 2. Due to the low statistical power of the group, the presented results are preliminary and need further investigation.

\section{Discussion}

The study published by our team in 2018 provides only available data about the changes in the concentration of TTN and DMD in patients with thyroid disorders [11].

The current research emphasises in particular the issue of the usefulness of TTN and DMD as new markers of muscle damage during thyroid disorders. Some of the measurements were conducted once more to evalu- ate their accuracy on a different group of patients. In general, the results of the present study are consistent with those of the previous one. However, in the hypothyroid group the decrease in $\mathrm{MM}$ after the restoration of euthyroidism did not reach statistical significance, probably due to the smaller sample size. Similarly, TTN and DMD levels at baseline differed between groups at the border of statistical significance. Nevertheless, the trend in TTN and DMD levels at baseline is comparable to the previous research - both concentrations are lower in hypo- and hyperthyroid patients.

After the restoration of euthyroidism, only in hypothyroid patients, we can observe a statistically significant increase in levels of DMD, and even some slight lowering of TTN when compared to levels at baseline. However, after treatment, TTN concentrations became significantly lower than in controls. In hyperthyroid groups, there is no statistically significant difference in TTN and DMD levels before and after treatment, but they remain noticeably lower than in the control group. The lack of definite normalisation of TTN and DMD after achieving euthyroidism might reflect some profound changes in muscle metabolism, occurring even after treatment.

The biochemistry and physiology of muscle cells are very complex, and thyroid hormones play a significant role in their homeostasis, including metabolic rate, energy expenditure, and glucose uptake.

Genes critical for muscle function and metabolism are regulated by triiodothyronine, which is derived from tetraiodothyronine due to DIO2 activity [12]. One of the crucial roles of T3 action on muscle fibres, dependent on thyroid status [13], is its possibility to change fibre type from slow-twitch (type 1) to fast-twitch type (type IIa, IIx, IIb) by regulation of genes MYH1, 2, 4, and 7 , which determine myosin heavy chain type [14]. We assume that this kind of TH-dependent muscle plasticity affects other cytoskeletal proteins such as titin and dystrophin.

With switching fibre-type, there is also a change in metabolic profile. Slow-twitch fibres are oxidative and contain more mitochondria and myoglobin. In turn, fast-twitch fibres are glycolytic, with higher concentrations of phosphocreatine [14].

Brennan et al. examined muscle biopsies of hyperthyroid patients before and after the correction of hyperthyroidism. The first finding is a decreased level of myosin heavy chain I (MHC I; slow-twitch fibres) and increased levels of MHCIIa and MHCIIx (fast-twitch) mRNAs in hyperthyroidism. After the restoration of the euthyroid state, consecutively, MHCI increased and MHCIIa/IIx decreased. The second finding was a decreased overall metabolic rate and reduced protein turnover [15]. 
Table 2. The characteristics and statistical differences of the measured values at baseline and after restoring euthyroidism in patients affected by hyperthyroidism and in patients affected by hypothyroidism. Statistically significant differences $(p<0.05)$ are marked $[*]$

\begin{tabular}{|c|c|c|c|c|c|c|}
\hline $\begin{array}{l}\text { Median } \\
\text { [25-75\%] }\end{array}$ & Before & After & $P$ value & Before & After & $p$ value \\
\hline $\begin{array}{l}\text { TSH } \\
{[\mathrm{pmol} / \mathrm{L}]}\end{array}$ & $\begin{array}{c}0.01 \\
{[0.01-0.01]}\end{array}$ & $\begin{array}{c}1.20 \\
{[0.27-2.76]}\end{array}$ & $0.0004^{*}$ & $\begin{array}{c}98.77 \\
{[80.05-100.00]}\end{array}$ & $\begin{array}{c}1.27 \\
{[0.82-2.31]}\end{array}$ & $0.0007^{*}$ \\
\hline $\begin{array}{l}\mathrm{fT3} \\
{[\mathrm{pmol} / \mathrm{L}]}\end{array}$ & $\begin{array}{c}27.21 \\
{[20.53-32.39]}\end{array}$ & $\begin{array}{c}4.27 \\
{[4.01-5.27]}\end{array}$ & $0.0002^{*}$ & $\begin{array}{c}1.56 \\
{[0.84-1.86]}\end{array}$ & $\begin{array}{c}4.34 \\
{[4.06-4.76]}\end{array}$ & $0.0012^{*}$ \\
\hline $\begin{array}{l}\mathrm{fT} 4 \\
{[\mathrm{pmol} / \mathrm{L}]}\end{array}$ & $\begin{array}{c}73.69 \\
{[53.73-81.03]}\end{array}$ & $\begin{array}{c}15.91 \\
{[13.87-17.30]}\end{array}$ & $0.0002^{*}$ & $\begin{array}{c}2.51 \\
{[1.83-4.32]}\end{array}$ & $\begin{array}{c}20.13 \\
{[16.56-21.00]}\end{array}$ & $0.0007^{*}$ \\
\hline fT3/fT4 ratio & $\begin{array}{c}0.38 \\
{[0.35-0.40]}\end{array}$ & $\begin{array}{c}0.30 \\
{[0.28-0.32]}\end{array}$ & $0.0173^{*}$ & $\begin{array}{c}0.43 \\
{[0.40-0.60]}\end{array}$ & $\begin{array}{c}0.22 \\
{[0.19-0.26]}\end{array}$ & $0.0117^{*}$ \\
\hline $\begin{array}{l}\text { CK } \\
{[\mathrm{IU} / \mathrm{L}]}\end{array}$ & $\begin{array}{c}47.00 \\
{[43.00-62.00]}\end{array}$ & $\begin{array}{c}95.00 \\
{[92.50-99.00]}\end{array}$ & $0.0010^{*}$ & $\begin{array}{c}299.00 \\
{[225.00-419.00]}\end{array}$ & $\begin{array}{c}100.00 \\
{[72.00-123.00]}\end{array}$ & $0.0015^{*}$ \\
\hline $\begin{array}{l}\mathrm{DMD} \\
{[\mathrm{ng} / \mathrm{mL}]}\end{array}$ & $\begin{array}{c}1.98 \\
{[1.36-5.75]}\end{array}$ & $\begin{array}{c}2.25 \\
{[1.90-2.75]}\end{array}$ & 0.2209 & $\begin{array}{c}1.89 \\
{[1.61-5.78]}\end{array}$ & $\begin{array}{c}2.60 \\
{[2.10-9.40]}\end{array}$ & $0.0010^{*}$ \\
\hline $\begin{array}{l}\text { TTN } \\
{[\mathrm{ng} / \mathrm{mL}]}\end{array}$ & $\begin{array}{c}12.07 \\
{[8.59-44.18]}\end{array}$ & $\begin{array}{c}13.00 \\
{[9.40-17.30]}\end{array}$ & 0.1094 & $\begin{array}{c}13.33 \\
{[8.22-40.33]}\end{array}$ & $\begin{array}{c}9.90 \\
{[7.3-31.95]}\end{array}$ & 0.2787 \\
\hline $\begin{array}{l}\text { Glucose } \\
{[\mathrm{mg} / \mathrm{dL}]}\end{array}$ & $\begin{array}{c}101.00 \\
{[94.00-102.50]}\end{array}$ & $\begin{array}{c}95.50 \\
{[91.50-100.50]}\end{array}$ & 0.0843 & $\begin{array}{c}85.50 \\
{[83.00-91.00]}\end{array}$ & $\begin{array}{c}90.00 \\
{[85.00-96.00]}\end{array}$ & 0.8385 \\
\hline $\begin{array}{l}\text { Irisin } \\
{[\mathrm{ng} / \mathrm{mL}]}\end{array}$ & $\begin{array}{c}152.40 \\
{[126.45-159.90]}\end{array}$ & $\begin{array}{c}165.78 \\
{[148.74-188.16]}\end{array}$ & 0.3259 & $\begin{array}{c}105.84 \\
{[85.44-113.76]}\end{array}$ & $\begin{array}{c}152.50 \\
{[127.26-186.06]}\end{array}$ & $0.0146^{*}$ \\
\hline $\begin{array}{l}\text { Body weight } \\
{[\mathrm{kg}]}\end{array}$ & $\begin{array}{c}59.40 \\
{[52.00-64.30]}\end{array}$ & $\begin{array}{c}62.10 \\
{[55.15-68.35]}\end{array}$ & $0.0002^{*}$ & $\begin{array}{c}64.58 \\
{[58.05-74.70]}\end{array}$ & $\begin{array}{c}61.45 \\
{[57.20-62.55]}\end{array}$ & 0.0506 \\
\hline $\begin{array}{l}\text { Fat } \% \\
(\%)\end{array}$ & $\begin{array}{c}23.50 \\
{[19.70-25.70]}\end{array}$ & $\begin{array}{c}26.90 \\
{[24.30-30.80]}\end{array}$ & $0.0010^{*}$ & $\begin{array}{c}26.40 \\
{[20.30-28.20]}\end{array}$ & $\begin{array}{c}26.25 \\
{[22.80-27.00]}\end{array}$ & 0.4838 \\
\hline $\begin{array}{l}\mathrm{FM} \\
{[\mathrm{kg}]}\end{array}$ & $\begin{array}{c}13.75 \\
{[9.95-15.55]}\end{array}$ & $\begin{array}{c}16.65 \\
{[13.35-20.75]}\end{array}$ & $0.0010^{*}$ & $\begin{array}{c}16.68 \\
{[12.90-19.75]}\end{array}$ & $\begin{array}{c}15.38 \\
{[13.05-16.25]}\end{array}$ & 0.2604 \\
\hline $\begin{array}{l}\text { FFM } \\
{[\mathrm{kg}]}\end{array}$ & $\begin{array}{c}45.95 \\
{[40.65-48.55]}\end{array}$ & $\begin{array}{c}45.40 \\
{[40.50-47.70]}\end{array}$ & 0.7113 & $\begin{array}{c}49.98 \\
{[42.90-53.20]}\end{array}$ & $\begin{array}{c}45.68 \\
{[42.25-49.45]}\end{array}$ & 0.0506 \\
\hline $\begin{array}{l}\mathrm{MM} \\
{[\mathrm{kg}]}\end{array}$ & $\begin{array}{c}43.60 \\
{[38.60-46.10]}\end{array}$ & $\begin{array}{c}43.10 \\
{[38.45-45.30]}\end{array}$ & 0.7113 & $\begin{array}{c}47.43 \\
{[40.70-50.50]}\end{array}$ & $\begin{array}{c}43.35 \\
{[40.10-46.95]}\end{array}$ & 0.0580 \\
\hline $\begin{array}{l}\mathrm{BMI} \\
{\left[\mathrm{kg} / \mathrm{m}^{2}\right]}\end{array}$ & $\begin{array}{c}22.10 \\
{[19.50-22.90]}\end{array}$ & $\begin{array}{c}23.10 \\
{[20.10-24.50]}\end{array}$ & $0.0001^{*}$ & $\begin{array}{c}23.50 \\
{[21.50-25.10]}\end{array}$ & $\begin{array}{c}21.50 \\
{[20.80-22.60]}\end{array}$ & 0.0506 \\
\hline Visceral fat rating & $\begin{array}{c}3.00 \\
{[1.00-5.00]}\end{array}$ & $\begin{array}{c}4.000000 \\
{[2.00-7.00]}\end{array}$ & $0.0022^{*}$ & $\begin{array}{c}4.00 \\
{[3.00-5.00]}\end{array}$ & $\begin{array}{c}3.00 \\
{[2.00-4.00]}\end{array}$ & 0.4227 \\
\hline
\end{tabular}

TSH — thyroid-stimulating hormone; fT3 — free triiodothyronine; fT4 — free thyroxine; TPOAb — anti-thyroid peroxidase antibodies; TgAb — anti-thyroglobulin antibodies; TRAb — anti-TSH receptor autoantibodies; CK — creatine kinase; DMD — dystrophin; TTN — titin; BMI — body mass index; FM — fat mass; Fat $\%$ — percent of fat mass; FFM — free-fat mass; MM — muscle mass

On the other hand, Monforte et al. investigated hypothyroid patients. Before treatment, histological findings revealed atrophy of type II fibres and abnormalities in glycogen deposition and oxidative pattern. Biochemical tests showed increased muscle glycogen and reduced activity of glycolysis and glycogenolysis enzymes. After treatment, laboratory parameters returned to normal, but some histological abnormalities persisted. The authors hypothesise that these histological pathologies may be the effect of irreversible damage in skeletal muscle, which is in line with our assumptions [16]. We theorise that after treatment of hyper- or hypothyroidism, metabolic parameters of muscles are restored to normal; however, with long-lasting thyrometabolic defects, some of them may become irreversible and manifest itself as the lack of normalisation of TTN and DMD. 
Additionally, we analysed the fT3/fT4 ratio. It was higher at the baseline in both hyper- and hypothyroid groups than in controls - comparable with the previous study of Mortoglou and Candiloros [17]. In hyperthyroid patients, the ratio is higher mainly due to excessive production of T3, and in hypothyroid subjects because of a decline in T4 concentration. After restoration of euthyroidism, the fT3/fT4 ratio in both groups decreased significantly, with median ratio values in hypothyroid patients lower than in the control group. A similar lowering of the fT3/fT4 ratio in hypothyroid patients after treatment was observed after analysing results by Hernik et al. [18]. It is probably due to the use of preparations containing only L-thyroxin in the management of hypothyroidism. There are still conflicting opinions about the combined L-thyroxin and L-triiodothyronine treatment; however, recommendations for such a therapeutic approach have recently been incorporated into the guidelines of the British Thyroid Association [19]. The use of combined preparation might result in the normalisation of the fT3/fT4 ratio.

Because, after the treatment of hypothyroid patients, the fT3/fT4 ratio was significantly lower than in controls accompanied by some shift in the levels of TTN and DMD and lowering of muscle mass, it might be possible that the change in $\mathrm{fT} 3 / \mathrm{fT} 4$ ratio alters the composition of muscle fibres. Thus, alteration in the synthesis and/or catabolism of large structural muscle fibre proteins is reflected by different dynamics of changes in TTN and DMD serum concentrations. However, such a hypothesis should be confirmed on a larger group of patients, preferably both on groups treated with Lthyroxin monotherapy and on those treated with combined L-thyroxin and L-triiodothyronine treatment.

Unfortunately, our study has several limitations. The smaller sample size, compared to the previous survey, affects the explicitness of the results obtained, although the trends observed remain constant. What is more, body composition could be assessed with the use of DXA or MRI examination for more accurate measurements than BIA spectroscopy. However, results of a recent study by Esco et al. show that BIA devices are acceptable alternatives to DXA for BF\%, FM, and FFM assessment in clinical practice [20]. Hence, the obtained data should be considered as preliminary.

\section{Conclusions}

Thyroid disorders can lead to great disturbances in muscle tissue, presented by changes in serum concentrations of small muscle enzymes, like CK or large structural proteins, like DMD or TTN; however, the presented dynamics of changes is different. What is more, changes in thyroid function, especially hypothyroidism, lead to disturbances resulting in decreased irisin levels - myokine produced by the muscle fibres. TTN and DMD may be the potential new markers of musculoskeletal deterioration in thyroid disorders. In addition, the shift in TTN and DMD serum concentrations after the treatment of hypothyroidism accompanied by a significant decrease in the fT3/fT4 ratio may suggest the influence of the chosen therapeutic approach on muscle metabolism. However, all of these promising and interesting issues should be evaluated further in more detailed studies on a large cohort of subjects.

\section{Acknowledgments}

This research was funded from the Statutory Funds of the Department of Endocrinology.

\section{Conflict of interest}

The authors do not have any conflict of interest related to this manuscript.

\section{References}

1. Duyff RF, Van den Bosch J, Laman DM, et al. Neuromuscular findings in thyroid dysfunction: a prospective clinical and electrodiagnostic study. J Neurol Neurosurg Psychiatry. 2000; 68(6): 750-755, doi: 10.1136/jnnp.68.6.750, indexed in Pubmed: 10811699.

2. Olson BR, Klein I, Benner R, et al. Hyperthyroid myopathy and the response to treatment. Thyroid. 1991; 1(2): 137-141, doi: 10.1089/thy.1991.1.137, indexed in Pubmed: 1688015.

3. Da Nóbrega AC, Vaisman M, De Araújo CG. Skeletal muscle function and body composition of patients with hyperthyroidism. Med Sci Sports Exerc. 1997; 29(2): 175-180, doi: 10.1097/00005768-199702000-000 02, indexed in Pubmed: 9044219.

4. Khaleeli AA, Edwards RH. Effect of treatment on skeletal muscle dysfunction in hypothyroidism. Clin Sci (Lond). 1984; 66(1): 63-68, doi: 10.1042/cs0660063, indexed in Pubmed: 6606523.

5. Kocabas H, Yazicioglu G, Karaman N, et al. Isokinetic evaluation of muscle strength in patients with thyroid dysfunction. Isokinetics Exerci Sci. 2009; 17(2): 69-72, doi: 10.3233/ies-2009-0335.

6. Gruener R, Stern LZ, Payne C, et al. Hyperthyroid myopathy. Intracellular electrophysiological measurements in biopsied human intercostal muscle. J Neurol Sci. 1975; 24(3): 339-349, doi: 10.1016/0022-510x(75)902 54-3, indexed in Pubmed: 1117309.

7. Brennan MD, Powell C, Kaufman KR, et al. The impact of overt and subclinical hyperthyroidism on skeletal muscle. Thyroid. 2006; 16(4): 375-380, doi: 10.1089/thy.2006.16.375, indexed in Pubmed: 16646684.

8. McGrowder DA, Fraser YP, Gordon L, et al. Serum creatine kinase and lactate dehydrogenase activities in patients with thyroid disorders. Niger J Clin Pract. 2011; 14(4): 454-459, doi: 10.4103/1119-3077.91755, indexed in Pubmed: 22248949.

9. Klein SM, Prantl L, Geis S, et al. Circulating serum CK level vs. muscle impairment for in situ monitoring burden of disease in Mdx-mice. Clin Hemorheol Microcirc. 2017; 65(4): 327-334, doi: 10.3233/CH-16195, indexed in Pubmed: 27716655.

10. Sönmez E, Bulur O, Ertugrul DT, et al. Hyperthyroidism influences renal function. Endocrine. 2019; 65(1): 144-148, doi: 10.1007/s12020-019-01903-2, indexed in Pubmed: 30904999.

11. Zybek-Kocik A, Sawicka-Gutaj N, Szczepanek-Parulska E, et al. The association between irisin and muscle metabolism in different thyroid disorders. Clin Endocrinol (Oxf). 2018; 88(3): 460-467, doi: 10.1111/cen.13527, indexed in Pubmed: 29197093.

12. Lee JW, Kim NH, Milanesi A. Thyroid Hormone Signaling in Muscle Development, Repair and Metabolism. J Endocrinol Diabetes Obes. 2014; 2(3): 1046-15, indexed in Pubmed: 25866834.

13. Simonides WS, van Hardeveld C. Thyroid hormone as a determinant of metabolic and contractile phenotype of skeletal muscle. Thyroid. 2008; 18(2): 205-216, doi: 10.1089/thy.2007.0256, indexed in Pubmed: 18279021.

14. Bloise FF, Cordeiro A, Ortiga-Carvalho TM. Role of thyroid hormone in skeletal muscle physiology. J Endocrinol. 2018; 236(1): R57-R68, doi: 10.1530/JOE-16-0611, indexed in Pubmed: 29051191. 
15. Brennan MD, Coenen-Schimke JM, Bigelow ML, et al. Changes in skeletal muscle protein metabolism and myosin heavy chain isoform messenger ribonucleic acid abundance after treatment of hyperthyroidism. J Clin Endocrinol Metab. 2006; 91(11): 4650-4656, doi: 10.1210/jc.2006-1074, indexed in Pubmed: 16940450.

16. Monforte R, Fernández-Solà J, Casademont J, et al. [Hypothyroid myopathy. A clinical and histologic prospective study of 19 patients]. Med Clin (Barc). 1990; 95: 126-129, indexed in Pubmed: 2250530.

17. Mortoglou A, Candiloros H. The serum triiodothyronine to thyroxine (T3/T4) ratio in various thyroid disorders and after Levothyroxine replacement therapy. Hormones (Athens). 2004; 3(2): 120-126, doi: 10.14310/horm.2002.11120, indexed in Pubmed: 16982586
18. Hernik A, Szczepanek-Parulska E, Filipowicz D, et al. The hepcidin concentration decreases in hypothyroid patients with Hashimoto's thyroiditis following restoration of euthyroidism. Sci Rep. 2019; 9(1) 16222, doi: 10.1038/s41598-019-52715-3, indexed in Pubmed: 31700042.

19. Okosieme O, Gilbert J, Abraham P, et al. Management of primary hypothyroidism: statement by the British Thyroid Association Executive Committee. Clin Endocrinol (Oxf). 2016; 84(6): 799-808, doi: 10.1111/cen.12824, indexed in Pubmed: 26010808.

20. Esco MR, Fedewa MV, Freeborn TJ, et al. Agreement between supine and standing bioimpedance spectroscopy devices and dual-energy $\mathrm{X}$ ray absorptiometry for body composition determination. Clin Physiol Funct Imaging. 2019; 39(5): 355-361, doi: 10.1111/cpf.12585, indexed in Pubmed: 31287228. 